\title{
EFEITO DE BACTÉRIAS RIZOSFÉRICAS E FERTILIZANTES NO ENRAIZAMENTO DE VIOLETA AFRICANA
}

Marco Aurélio BORACIN ${ }^{1}$

Dora Inés KOZUSNY-ANDREANI²

Roberto ANDREANI JUNIOR ${ }^{3}$

\begin{abstract}
${ }^{1}$ Graduado em Agronomia, Universidade Camilo Castelo Branco, Campus Fernandópolis, SP. marco_boracin@hotmail.com

${ }^{2}$ Licenciada em Genética, Doutora, Professora Titular do Mestrado em Ciências Ambientais - Laboratório de Microbiologia - Universidade Camilo Castelo Branco (Unicastelo) Campus Fernandópolis, SP. doraines@ terra.com.br ${ }^{3}$ Engenheiro Agrônomo, Doutor, Professor Titular do Curso de Mestrado em Ciências Ambientais - Universidade Camilo Castelo Branco (Unicastelo) Campus Fernandópolis, SP. robertoandreani@uol.com.br
\end{abstract}

Recebido em: 10/08/2015 - Aprovado em: 06/01/2016 - Disponibilizado em: 30/07/2016

\begin{abstract}
RESUMO
O presente trabalho foi conduzido com o objetivo de avaliar a efeito de bactérias rizosféricas e biofertilizantes no enraizamento estacas foliares de violeta africana (Saintpaulia ionantha Wendl).Foram utilizadas rizobactérias isoladas de raízes de limão cravo, empregadas para preparação do inoculanteem meio de cultura líquido triptecaseina soja. As estacas foliares foram colocadas em contato com o inoculantes por 15 minutos, e em seguida com o auxílio de pinça estéril, estas foram transferidas para as bandejas preenchidas com substrato. O biofertilizante Vetor 1000 eo fertilizante CoMo foram utilizados na concentração $1 \mathrm{~mL} \mathrm{~L} \mathrm{~L}^{-1}$ de água, sendo que estacas foram tratadas 5 e 10 minutos respectivamente. $\mathrm{O}$ delineamento foi inteiramente casualizado com 17 tratamentos e 12 repetições. $\mathrm{O}$ experimento foi conduzido em câmara de crescimento, com fotoperíodo de 16 horas luz etemperaturaconstante de $28^{\circ} \mathrm{C}$. Foi avaliada a massa fresca e seca das raízes. Os dados obtidos foram tabulados e submetidos a análise de variância paramétrica, complementada com o teste de comparação múltipla de Tukey. Verificou-se que as rizobacterias isoladas de limão cravo induziram o desenvolvimento radicular e a formação de brotos nas estacas de violeta africana. As estacas tratadas com Vetor 1000 por 5 minutos não apresentaram bom desenvolvimento radicular nem de brotos, enquanto que 10 minutos de tratamento foi positivo para estas variáveis; o fertilizante CoMo induziu a formação de raízes.
\end{abstract}

Palavras-chave: Saintpaulia ionantha Wendl. Enraizamento. Brotação. Rizobactérias. Biofertilizante.

\section{EFFECT OF RIZHOSPHERIC BACTERIA AND FERTILIZERS ON ROOTING OF AFRICAN}

VIOLET

\begin{abstract}
The present study was conducted with the aim of evaluating the effect of rizhospheric bacteria and biofertilizers on rooting leaf cuttings of African Violet (Saintpaulia ionantha Wendl). Rhizobacteria were used isolated from roots of mandarin lime, employed for the preparation of inoculant in liquid culture medium (Trypticase Soy Agar). The leaf cuttings were placed in contact with the inoculants for 15 minutes, and then with the aid of sterile clamp, these were transferred to the substrate-filled trays. The biofertilizer Vector 1000 and fertilizer CoMo were used on $1 \mathrm{~mL} \mathrm{~L}^{-1}$ concentration of water, and the cuttings were treated for 5 and 10 minutes respectively. The delineation was completely randomized with 17 treatments and 12 repetitions. The experiment was conducted in growth chamber, with photoperiod of 16 hours light and constant temperature of $28^{\circ} \mathrm{C}$. It was evaluated the fresh and dry mass of the roots. The data obtained were tabulated and subjected to parametric variance analysis, complemented with the Tukey's multiple comparison test. It was found that the rizhobacteria isolated from mandarin lime induced the root development and the formation of buds in the African Violet cuttings. The cuttings treated with Vector 1000 for 5 minutes did not show good root or buds development, while 10 minutes of treatment was positive for these variables; the fertilizer CoMo induced the formation of roots.
\end{abstract}

Key words: Saintpaulia ionantha Wendl. Rooting. Buds. Rhizospheric bacteria. Biofertilizers 


\section{INTRODUÇÃO}

A violeta africana (Saintpaulia ionantha Wendl.), é uma planta florífera ornamental originária do leste da África, herbácea, perene, acaule e de fácil cultivo. Pertencente à família Gesneriaceae, da qual cerca de 300 espécies são cultivadas dentre as mais de 2000 conhecidas, com florescimento contínuo durante $o$ ano todo, embora possa ser multiplicada por sementes a sua propagação é realizada assexuadamente pela utilização de estacas foliares formadas por uma folha e seu pecíolo (LOPES, 2005)

Na produção de mudas de violeta africana se utilizam diferentes fitorreguladores, os quais possuem papel importante na coordenação do crescimento e do desenvolvimento vegetal, controlando muitos processos bioquímicos e fisiológicos. O resultado de sua ação está diretamente relacionado com o tipo, concentração, combinação entre reguladores exógenos utilizados e sua interação com os níveis endógenos de hormônios (SUNPUI e KANCHANAPOOM, 2002).

Nos últimos anos as bactérias promotoras de crescimento, conhecidas na literatura como "plant growth - promoting rhizobacteria" (PGPR) ou "rhizobacterias promotoras de crescimento de plantas" (RPCP) começaram a ser pesquisadas com a finalidade de produção de plantas anuais e perenes.
Estas bactérias colonizam diferentes órgãos das plantas e exercem efeitos benéficos sobre as mesmas, podendo promover aumentos na taxa de germinação de sementes, no desenvolvimento de órgãos, na produção de flores e no rendimento das culturas em casa de vegetação e no campo (AMORIM e MELO 2002; DEY et al. 2004; KOZUSNYANDREANI et al.; 2014, GUPTA et al., 2014; HAIYAMBO et al., 2015).

Os efeitos benéficos das RPCP podem ser observados em plantas propagadas "in vitro" e "ex vitro" principalmente pelo aumento de área foliar, altura da planta, diâmetro do caule, número de folhas e matéria seca, redução do tempo de aclimatização, maior sobrevivência de mudas, controle de doenças e aumento de produtividade (MARIANO, 2004; TAURIAN et al., 2010; BASHAN et al., 2014).

Uma vez que a sustentabilidade é uma direção a ser seguida na produção de plantas, o uso de rizobactérias é considerado uma alternativa para a redução ou substituição do uso de produtos químicos sintéticos, seja diretamente como promotoras de crescimento, seja como agentes de controle biológico de doenças (MARIANO e KLOEPPER, 2000, MARIANO, 2004, SCHLINDWEIN et al. 2008). O presente trabalho foi conduzido com o objetivo de avaliar a efeito de bactérias rizosféricas e biofertilizantes no enraizamento 
de violeta africana (Saintpaulia ionantha

Wendl)

\section{MATERIAL E MÉTODOS}

O experimento foi conduzido no Laboratório de Biotecnologia da Universidade Camilo Castelo Branco, campus Fernandópolis, SP (Fazenda Santa Rita), localizada entre as coordenadas 20 $20^{\circ} 50^{\prime \prime}$ latitude sul e $50^{\circ} 17^{\prime} 43 "$ longitude oeste e $20^{\circ} 18^{\prime} 05^{\prime \prime}$ de latitude sul e $50^{\circ} 16^{\prime} 26^{\prime \prime}$ de longitude oeste e a uma altitude de $520 \mathrm{~m}$. As plantas matrizes de violeta africana foram adquiridas no Veiling Holambra em Santo Antonio de Posse/SP. As mudas foram mantidas por uma semana a temperatura ambiente para aclimatação e diminuição do estresse.

Foram utilizadas rizobactérias isoladas de raízes de limão cravo, pertencente ao laboratório de Microbiologia da Universidade Camilo Castelo Branco-UNICASTELO, campus Fernandópolis, SP. Todos os isolados estavam preservados em geladeira a $5^{\circ} \mathrm{C}$, em tubos de ensaio contendo meio de cultura ágar nutritivo. As estirpes utilizadas foram UCCBc 415, UCCBc 132, UCCBc 432, UCCBc 212, UCCBc235, UCCBc 342, UCCBc 232, UCCBc244, UCCBc323, UCCBc 333 e $\mathrm{UCCBc} 215$.

Para preparação do inoculante utilizouse meio de cultura líquido TS (triptecaseina soja, $\quad$ Oxoid $\left.^{\circledR}\right)$, que foi submetido à esterilização em autoclave (20 minutos a $120^{\circ} \mathrm{C}$ e 1 atmosfera de pressão). Após este procedimento, os meios foram resfriados e inoculados com as estirpes bacterianas selecionadas. Os meios contendo os microorganismos, foram incubados sob agitação (200 rpm), onde permaneceram por um período de 24 horas com temperatura de 28 $\pm 0,5{ }^{\circ} \mathrm{C}$. Após este período a concentração bacteriana foi ajustada para $10^{6} \mathrm{UFC} \mathrm{mL}^{-1}$ (unidades formadoras de colônias) quando as estacas foliares foram colocadas em contato com o mesmo onde permaneceram por um período de tempo de 10 minutos, e em seguida com o auxílio de pinça estéril, estas foram transferidas para as bandejas.

O biofertilizante Vetor 1000 (Tab.1) é um produto a base de peixe, sendo proveniente da fermentação deste, mais glicose e semeação do fungo (Aspergillus oryzae), ativado por uma energização solar controlada que resulta em aminoácidos de peixe. Entre os benefícios de seu uso estão melhorar o enraizamento, resistência às adversidades (stress climático, transplante etc.), melhorar a fotossíntese e o metabolismo, dar resistência às plantas ao ataque de pragas e doenças, melhorar o crescimento vegetativo e produção. Além disso, o produto por ser natural não ocasiona 
danos ao meio ambiente, podendo ser utilizado tanto na agricultura orgânica como na convencional (LIEKNIN, 2008). O biofertilizante (Tabela 1) foi utilizado na concentração recomendada pelo fabricante (1 $1 \mathrm{~mL}$ do biofertilizante diluído em 1L de água).

Tabela 1: Composição química do biofertilizante Vector1000 (fermentado de peixes).

\begin{tabular}{lc}
\hline \multicolumn{1}{c}{ Composição } & $\mathrm{mg} 100 \mathrm{~mL}^{-1}$ \\
\hline Ácido aspártico & 328,57 \\
Treonina & 203,89 \\
Serina & 139,93 \\
Ácido glutâmico & 346,94 \\
Prolina & 219,99 \\
Glicina & 389,07 \\
Alanina & $\mathrm{ND}$ \\
Cistina & 239,35 \\
Valina & 227,95 \\
Metionina & 186,61 \\
Isoleucina & 431,36 \\
Tirosina & 115,11 \\
Fenilalanina & 205,97 \\
Lisina & 296,94 \\
Histidina & 110,87 \\
Triptofano & 16,66 \\
Arginina & 222,66 \\
Amônia & 131,62 \\
\hline
\end{tabular}

* ND= não detectado Fonte: o fabricante

O fertilizante Adubem CoMo Premium é um produto a base de Sulfato de cobalto, molibdato de sódio, ácido giberélico e carbono orgânico (Tabela 2). O CoMo é um fertilizante que favorece a fixação do nitrogênio pela planta uma vez que este possui como um de seus micronutrientes, o molibdênio atuando como co-fatorintegrante nas enzimas nitrogenase, redutase do nitrato e oxidase do sulfato.

O CoMo Premium possui ainda em sua formulação, o cobalto, elemento químico presente na estrutura molecular da vitamina
B12 e cobamida, suabtâncias essas responsáveis pelo desenvolvimento das bactérias fixadoras de nitrogênio (gênero Rhizobium), organismos estes, que se desenvolvem na estrutura radicular das leguminosas.

Além dos micronutrientes especificados acima, o CoMo Premium possui um enraizante (ácido giberélico) que proporciona maior desenvolvimento radicular e, contudo favorece a absorção dos nutrientes presentes no solo.Foi utilizado na concentração recomendada pelo fabricante de $(2 \mathrm{ml}$ de Adubem CoMo Premium diluído em $1 \mathrm{~L}$ de água).

Tabela 2: Composição química do CoMo Premium (Adubem).

\begin{tabular}{lc}
\hline \multicolumn{1}{c}{ Composição } & $\mathrm{g} \mathrm{L}^{-1}$ \\
\hline Cobalto & 12,5 \\
Molibdênio & 125 \\
Acido Giberélico & 0,0625 \\
Carbono Orgânico & 250 \\
Enxofre & 6,875 \\
\hline
\end{tabular}

Fonte: o fabricante

O experimento foi composto de doze repetições por tratamento, com delineamento inteiramente casualizado. Os tratamentos foram: 1- testemunha sem tratamento das estacas; 2- biofertilizante Vetor 1000 (5 minutos), 3- biofertilizante Vetor 1000 (10 minutos); 4- CoMo (5 minutos), 5- CoMo (10 minutos); 6 a 16- inoculados com as estirpes bacterianas isoladas de limão cravoUCCBc 415, UCCBc 132, UCCBc 432, UCCBc 212, UCCBc235, UCCBc 342, UCCBc 232, UCCBc244, UCCBc323, UCCBc 333 e 
UCCBc 215, distribuídos em bandejas de propilenocom capacidade de 48 células.

O experimento foi conduzido no Laboratório de Biotecnologia da Universidade Camilo Castelo Branco, Campus de Fernandópolis, S P. Foram utilizadas estacas foliares de violeta africana cv Sônia, padronizadas pelo tamanho do limbo foliar.

O substrato Bioplant ${ }^{\circledR}$ foi esterilizado em autoclave, em temperatura de $121{ }^{\circ} \mathrm{C}$ e uma atmosfera de pressão por 60 minutos, uma vez frio o mesmo foi utilizado para preencher as bandejas de polipropileno, as quais foram desinfetadas em álcool $70 \%$ por 1 minuto.

As estacas foliares foram colocadas em contato por 10 minutos com os inoculantes e 5 e 10 minutos com Vetor 100 e CoMo, após estes procedimentos foram transferidas para as bandejas.

O experimento foi conduzido em câmara de crescimento com fotoperíodo de 16 horas luz e temperatura constante de $28{ }^{\circ} \mathrm{C}$. Diariamente foi fornecido $2 \mathrm{~mL}$ de água, com a finalidade de manter o substrato umedecido evitando assim interferência ambiental nos resultados.

Aos quarenta e cinco dias após o plantio, cada estaca foi retirada cuidadosamente, as raízes foram lavadas para retirada dos resíduos de substrato e o excedente de água foi retirado com papel absorvente, posteriormente as raízes foram separadas com auxilio de uma tesoura.
Foram avaliadas as seguintes variáveis: massa fresca e seca de raízes. A massa fresca da raiz (g) foi obtida pela pesagem de todo o material fresco de cada estaca, realizado em balança analítica. Enquanto que a massa seca da raiz (g) foi obtida após permanência em estufa a uma temperatura de $56{ }^{\circ} \mathrm{C}$, por 24 horas. Após esse período, o material foi retirado da estufa e pesado em balança analítica, sendo os resultados expressos em g estaca ${ }^{-1}$.

$\mathrm{O}$ dados obtidos foram tabulados $\mathrm{e}$ submetidos a técnica de análise de variância paramétrica, complementada com o teste de comparação múltipla de Tukey, para comparar os tratamentos nas variáveis massa fresca e seca das raízes. O software estatístico utilizado para análise foi o Sigma Stat versão 3.5 .

\section{RESULTADOS E DISCUSSÃO}

As estacas de violeta bacterizadas com rizobactérias promotoras do crescimento de plantas (RPCP), cultivadas em câmara de crescimento, apresentaram diferentes respostas em relação às variáveis analisadas, mostrando influência dos diversos isolados no desenvolvimento das raízes (Tabela 3). Esse é um fato comum no ambiente da rizosfera de qualquer planta, onde, em geral, ocorre um equilíbrio entre micro-organismos benéficos e deletérios (WHIPPS 2001). Uma pequena mudança neste balanço pode desencadear uma doença ou, por outro lado, resultar no controle biológico de patógeno ou promoção do 
crescimento da planta. A maioria dos trabalhos com RPCP discutem apenas o efeito benéfico dessas bactérias, não comentando sua ação deletéria. Embora não diferindo estatisticamente da testemunha não bacterizada, o isolado UCBc 212 exerceu um efeito positivo sobre o enraizamento e a produção de biomassa das raízes, traduzida, pelo aumento da matéria seca e brotações (Tabela 3 e Figura 1).

O fato de isolados de limão cravo terem promovido o enraizamento e desenvolvimento de brotações das estacas de violeta africana (Figura 1), sugere a sua não especificidade, como relatada por Quadt-Hallmann e Kloepper (1996), que descrevem que isolados originais de um hospedeiro podem facilmente colonizar outros hospedeiros de espécies diferentes, até mesmo com maior intensidade. Assim, os mesmos autores relatam que quando a bactéria endofítica Enterobacter asburiae, isolado JM22 de algodão foi inoculada em feijão e pepino, foram detectadas maiores populações do que em seu hospedeiro original. Da mesma forma Shishido e Chanway (1998) observaram que a promoção do crescimento de plântulas de abeto, resultante da aplicação de bactérias oriundas do mesmo ecossistema foi baixo, não sendo, portanto, necessário combinar outros isolados, como Pseudomonas, com ecótipos de abeto e tipos de solo, para uma efetiva promoção de crescimento de plântulas, confirmando dessa forma, a não especificidade, como encontrado neste trabalho.

Tabela 3: Média e desvio padrão das variáveis: massa fresca e massa seca de raízes (g) para estacas de violeta africana submetidas às diferentes tratamentos.

\begin{tabular}{lcc}
\hline \multirow{2}{*}{ Tratamentos } & $\begin{array}{c}\text { Massa fresca } \\
\text { de raízes }(\mathrm{g})\end{array}$ & $\begin{array}{c}\text { Massa seca } \\
\text { de raízes }(\mathrm{g})\end{array}$ \\
\hline UCCBc 415 & $0,094 \pm 0,022 \mathrm{a}$ & $0,012 \pm 0,003 \mathrm{ab}$ \\
UCCBc 132 & $0,079 \pm 0,026 \mathrm{a}$ & $0,012 \pm 0,005 \mathrm{ab}$ \\
UCCBc 432 & $0,065 \pm 0,016 \mathrm{a}$ & $0,010 \pm 0,002 \mathrm{ab}$ \\
UCCBc 244 & $0,068 \pm 0,026 \mathrm{a}$ & $0,017 \pm 0,007 \mathrm{ab}$ \\
UCCBc 323 & $0,042 \pm 0,021 \mathrm{a}$ & $0,012 \pm 0,005 \mathrm{ab}$ \\
UCCBc 333 & $0,094 \pm 0,040 \mathrm{a}$ & $0,014 \pm 0,002 \mathrm{ab}$ \\
UCCBc 215 & $0,082 \pm 0,029 \mathrm{a}$ & $0,013 \pm 0,006 \mathrm{ab}$ \\
UCCBc 212 & $0,112 \pm 0,044 \mathrm{a}$ & $0,019 \pm 0,003 \mathrm{a}$ \\
UCCBc 235 & $0,056 \pm 0,009 \mathrm{a}$ & $0,014 \pm 0,001 \mathrm{ab}$ \\
UCCBc 232 & $0,025 \pm 0,004 \mathrm{a}$ & $0,007 \pm 0,0001 \mathrm{ab}$ \\
UCCBc 342 & $0,042 \pm 0,028 \mathrm{a}$ & $0,010 \pm 0,005 \mathrm{ab}$ \\
V1000 10min & $0,047 \pm 0,018 \mathrm{a}$ & $0,009 \pm 0,003 \mathrm{ab}$ \\
CoMo 10 min & $0,063 \pm 0,052 \mathrm{a}$ & $0,014 \pm 0,005 \mathrm{ab}$ \\
V10005 min & $0,029 \pm 0,012 \mathrm{a}$ & $0,005 \pm 0,001 \mathrm{~b}$ \\
CoMo 5 min & $0,114 \pm 0,057 \mathrm{a}$ & $0,017 \pm 0,009 \mathrm{ab}$ \\
Testemunha & $0,119 \pm 0,032 \mathrm{a}$ & $0,016 \pm 0,003 \mathrm{ab}$ \\
\hline
\end{tabular}

* Duas ou mais médias seguidas letras diferentes nas colunas diferem entre si quanto aos respectivos tratamentos utilizadas $(\mathrm{p}<0,05)$.

V1000: Vetor1000

No entanto, alguns autores enfatizam a necessidade da utilização de isolados residentes ou adaptados ao hospedeiro, justificando a maior capacidade de colonização, menor risco na introdução de organismos exógenos (KHALID et al. 2004) e especificidade entre o isolado de RPCP e o hospedeiro (ENEBAK et al. 1998). 
Figura 1: Estacas de violeta africana bacterizadas com as estirpes UCCBc212, UCCBc132, UCCBc415 e testemunha não bacterizadas.

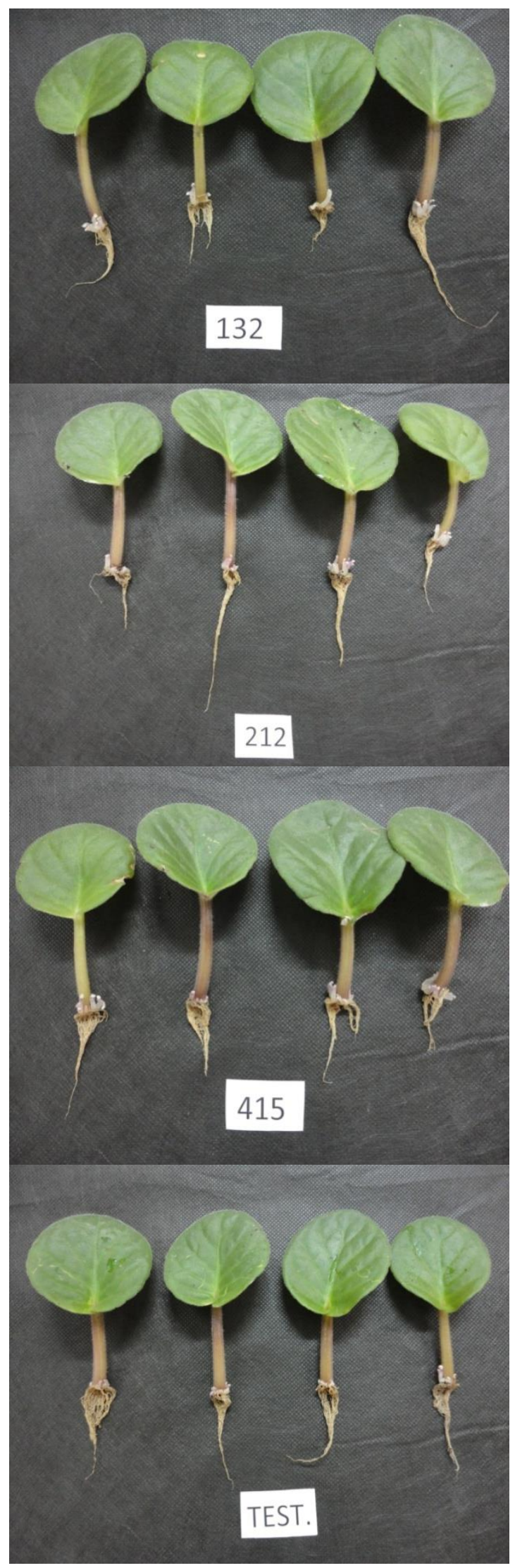

Nas estacas tratadas com o isolado UCCBc 212 observou-se, em relação às tratadas por 5 minutos com o biofertilizanteVetor 1000, aumento na biomassa da matéria seca das raízes (Tabela 3 e Figura2), enquanto que ao comparar com os tratamentos Vetor 1000 (10 minutos),CoMo (5 e 10minutos) e a bacterização com RPCPs não apresentaram aumento nas variáveis biomassa fresca e seca das raízes (tabela 3 ). No entanto, verificou-se maior brotação nas estacas bacterizadas e tratadas com Vetor 1000 por 10 minutos e com CoMo. Lakawatana e Criley (1999) observaram incremento na emissão de brotos vegetativos do pseudocaule de Heliconea stricta "Dwarf Jamaican" e atribuíram esse efeito ao aumento do número de folhas em produzidas em vasos, e consideraram que esse fato foi decorrente do maior desenvolvimento do sistema assimilador. $\mathrm{O}$ fato de os tratamentos não apresentarem aumentos significativos de biomassa radicular (Tabela 3), pode ser atribuído a diversos fatores, entre os quais a utilização de pequeno número de isolados. Outro fator que poderia ter resultado em benefício do desenvolvimento seria a utilização de isolados endofíticos e epifíticos provenientes de violeta africana. Apesar de certos autores não considerarem a especificidade bactéria-hospedeiro como essencial para a promoção de crescimento (QUADT-HALLMANN \& KLOEPPER 
1996, SHISHIDO \& CHANWAY 1998), outros pesquisadores enfatizam a importância

Figura 2: Estacas de violeta africana tratadas com o biofertilizante Vetor 1000 e fertilizante CoMo.

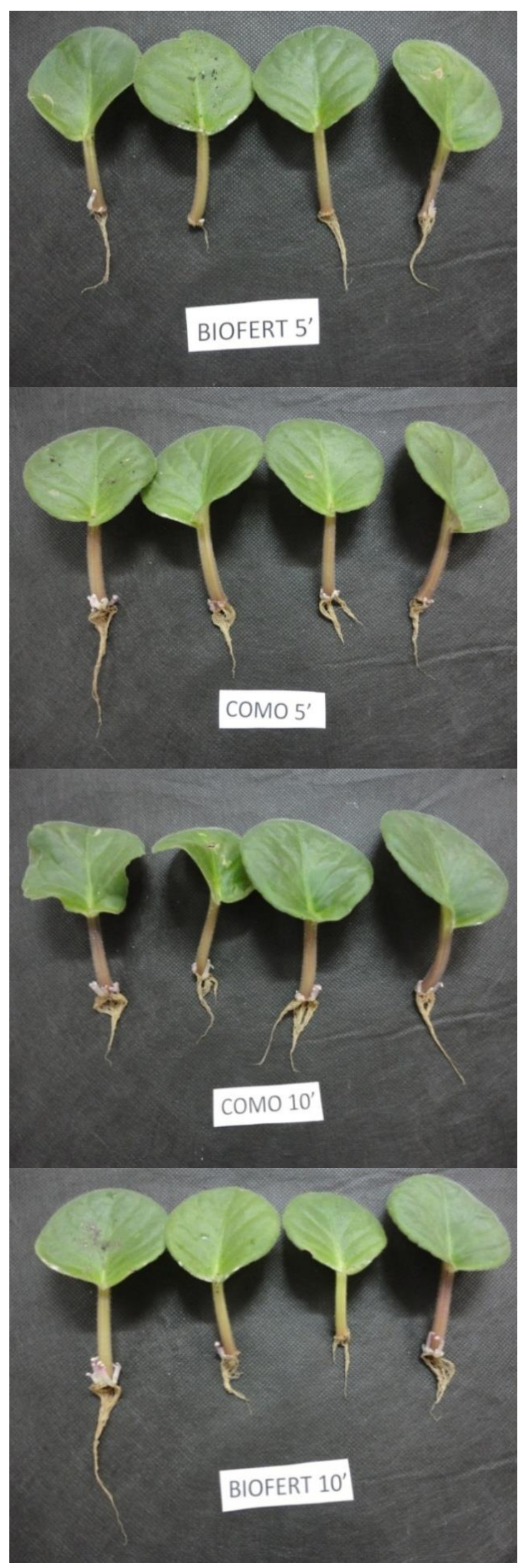

da especificidade para a obtenção de bons resultados (ENEBAK et al. 1998, SRINATH et al.2003).

Embora não tendo sido determinado o tipo de colonização realizada pelo isolado $\mathrm{UCCBc}$ 212, ele pode ter colonizado tanto interna como externamente as unidades propagativas tratadas, uma vez que essas bactérias apresentam tanto à capacidade de colonizar os tecidos externos quanto internos da planta, podendo sintetizar reguladores de crescimento ou induzir a síntese desses compostos (BARAZANI \& FRIEDMAN 1999). Khalidetal, (2004), sugerem que até $80 \%$ das bactérias isoladas da rizosfera são capazes de produzir AIA.

\section{CONCLUSÃO}

De acordo com a metodologia utilizada e com os resultados obtidos pode concluir-se que as rizobacterias isoladas de limão cravo o biofertilizante Vetor1000 e o fertilizante CoMo induziram o desenvolvimento radicular e a formação de brotos nas estacas de violeta africana

\section{REFERÊNCIAS}

AMORIM, E.P.R. e MELO, I. S. Ação antagônica de rizobactérias contra Phytophthora parasítica e $P$. citrophthorae seu efeito no desenvolvimento de plântulas de citros. Revista Brasileira de Fruticultura, v. 24, p. 565-568, 2002.

BARAZANI, O. \& FRIEDMAN, J. Is IAA the major root growth factor secreted from plant-growth-mediating bacteria?. Journal of 
Chemical Ecology, v. 25, p. 2397-2406, 1999.

BASHAN, Y.; DE-BASHAN, L.E.; PRABHU, S. R.; HERNANDEZ, J.P. Advances in plant growth-promoting bacterial inoculant technology: formulation sand practical perspectives (1998-2013). Plant and Soil, v.378, p.1-33, 2014.

DEY, R., PAL, K.K., BHATT, D.M. E CHAUHAN, S.M. Growth promotion and yield enhancement of peanut (Arachis hypogaea L.) by application of plant growth promoting rhizobacteria. Microbiological Research v.159, p. 371-394, 2004.

ENEBAK, S.A., WEI, G. \& KLOPPER, J. W. Effects of plant growth - promoting rhizobacteria on loblolly and slash pine seedlings. Forest Science v. 44, p.141-143, 1998.

GUPTA, S.; MEENA, M.K.;DATTA, S. Isolation, characterization of plant growth promoting bacteria from the plant Chlorophytum borivilianum and in-vitro screening for activity of nitrogen fixation, phospthate solubilization and IAA production. International Journal of Current Microbiology and Applied Sciences. v. 3, n.7, p. 1082-1090, 2014.

HAIYAMBO, D.H.; REINOLD-HUREK, B.; CHIMWAMUROMBE, P.M. Effects of plant growth promoting bacteria isolates from Kavango on the vegetative growth of Sorghum bicolor. African Journal of Microbiology Research, v.9, n.10, p.725729, 2015.

KHALID, A., ARSHAD, M.; ZAHIR, Z.A. Screening plant growth-promoting rhizobacteria improving growth and yield of wheat. Journal of Applied Microbiology, v. 96, p. 473-480, 2004.

KOZUSNY-ANDREANI, D.I.; AGIADO, J.C.; ANDREANI JUNIOR, R.Efeito de bactérias rizosféricas sobre $O$ desenvolvimento da cenoura. Revista da
Universidade Vale do Rio Verde, v. 12, n. 1, p. 211-220, 2014.

LAKAWATANA, S. \&CRILEY, R.A. Pot culture of Heliconia stricta "Dwarf Jamaican". Acta Horticulturae, v. 252, p. 123-128, 1999.

LIEKNIN.Vetor 1000, aminoácidos de peixe. Industria e comercio de fertilizante orgânico, Campinas-SP,

2008.Disponivel:www.itaf.org.br.Acessado em 15 de Novembro de 2011.

LOPES, J. C. Enraizamento de estacas foliares de violeta africana (Saintpaulia ionantha Wendl.) em diferentes substratos. Revista Ciência e Agrotecnologia, Lavras, v. 29 n. 2, p.23-28, 2005.

MARIANO R.L.R. KLOEPPER, J.W. Método alternativo de biocontrole: resistência sistêmica induzida por rizobactérias. Revisão Anual de Patologia de Plantas v. 8, p.121137, 2000.

MARIANO, R. de L. R.. Importância de bactérias promotoras de crescimento e de biocontrole de doenças de plantas para uma agricultura sustentável. Anais da Academia Pernambucana de Ciência Agronômica, Recife, vol. 1, p.89-111, 2004.

QUADT-HALLMANN, A.; KLOPPER, J.W. Immunological detection and localization of the cotton endophyte Enterobacter asburiae JM22 in different plant species.Canadian Journal of Microbiology, v. 42, p. 11441154, 1996

SCHLINDWEIN G; VARGAS LK; LISBOA BB; AZAMBUJA AC; GRANADA CE; GABIATTI NC; PRATES F; STUMPF R. Influência da inoculação de rizóbios sobre a germinação e o vigor de plântulas de alface. Ciência Rural, v. 38, p.658-664, 2008.

SHISHIDO, M. \& CHANWAY, C.P. Spruce growth response specificity after treatment with plant growth promoting Pseudomonads. Canadian Journal of Botany v. 77, p. 22-31, 1998 
SRINATH, J., BAGYARAJ, D.J. \& SATYANARAYANA, B.N. Enhanced growth and nutrition of micropropagated Ficus benjamina to Glomus mosseae coinoculated with Trichoderma harzianum and Bacillus coagulans. World Journal of Microbiology \& Biotechnology v.19, p.6972, 2003.

SUNPUI, W.; KANCHANAPOOM, K. Plant regeneration from petiole and leaf of African violet.(Saintpauli aionantha Wendl.) cultured in vitro. Journal Science Technology, [S.1.], v. 24, n. 3, p. 357-364, 2002.
TAURIAN,T.; ANZUAY, M.S.; ANGELINI, J.G.; TONELLI, M.L.; LUDUEÑA, L.; PENA, D.; IBÁÑEZ， F.; FABRA,A. Phosphate-solubilizing peanut associated bacteria: screening for plant growth promoting activities. Plant and Soil, v.329, p.421-431, 2010.

WHIPPS, J.M. Microbial interactions and biocontrol in the rhizosphere. Journal of Experimental Botany, v. 52, p. 487-511, 2001. 